An ESRC Research Group

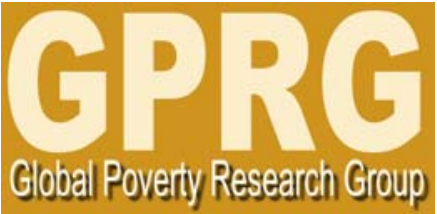

\title{
Fate and Fear: Risk and its Consequences in Africa
}

\author{
GPRG-WPS-074
}

Stefan Dercon

Global Poverty Research Group

Website: http://www.gprg.org/

The support of the Economic and Social Research Council (ESRC) is gratefully acknowledged. The work was part of the programme of the ESRC Global Poverty Research Group. 


\title{
Fate and Fear:
}

\section{Risk and its Consequences in Africa}

\author{
Stefan Dercon \\ University of Oxford
}

We review the evidence on risk and its consequences in Africa. We argue that too much attention has been given to the risk management and coping mechanisms used by households, and not enough on its implications and the scope for interventions. Much of the empirical work on risk in developing countries has also focused largely on the short-run implications, and has ignored the long-run. Risk and shocks have important long-run implications for growth and poverty, and distinguishing risk from shocks adds further insights. A few key missing dimensions in the work on risk and its consequences in Africa are also explored. First, microeconomic research on risk has limited itself to work on risks that are 'easy' to analyze, such as weather shocks. These risks are still dominating the life of many of the poor, dependent on agricultural production, but these risks are not necessarily central to the growth and poverty tragedy in Africa: which is driven by the lack of African and foreign investment in Africa. In particular, the risks related to poorly functioning markets and economic and political institutions have been underresearched by microeconomists, often leaving the initiative to macroeconomic research. A few examples are offered that appear to start tackling these questions. Finally, research on risk and its implications has to embrace more seriously the experimental and behavioural literature. The research frameworks used in most work on risk and its implications are based on shaky behavioural foundations, building on the expected utility framework - but testing these foundations in the environments were risk really matters, such as the poorest settings of Africa, has largely been lacking, limiting our understanding of whether they matter.

February 2007, version 2 


\section{Introduction}

This paper revisits some recent micro-level research on risk and its implications for growth and poverty in Africa. There is no area in the world as much identified with risk and shocks, such as largely covariate risks related drought, natural disasters, as well as conflict and political instability, and high levels of child and adult mortality and morbidity. It is only in the last decade or so that a more systematic analysis has begun on the implications of this high-risk environment on economic behaviour and performance. This paper revisits some of this work.

Nevertheless, this is not meant to be a review article. In recent years, there are have been quite of few literature reviews that are worth consulting, for example Morduch (1995), Townsend (1995), Fafchamps (2003), or Dercon (2002). Even though some of this evidence will be discussed, the focus in this paper is different, focusing on the gaps in this research. One central issue addressed is to identify avenues for further research, not least in Africa.

The paper makes six points. First, much of the academic research has its balance wrong, focusing too much on admittedly fascinating issues related to risk management and coping mechanisms, but not enough on its implications and the scope for interventions. Second, much of the empirical work on risk in developing countries has focused largely on short-run implications, and has ignored the long-run. Thirdly, and related, the policy interest in this academic research has been driven largely by a narrow social protection agenda, reducing it to a 'soft', peripheral and almost irrelevant topic, far removed from concerns with growth and fighting poverty. Fourth, research has often failed to distinguish the implications of risk and shocks, failing to distinguish fate and fear, conflating the consequences of serious negative events ('shocks') with the implications for economic behaviour related to living in a highly insecure environment ('risk'). Fifth, much of the microeconomic research on risk has limited itself to work on risks that are 'easy' to analyze, such as weather shocks. These risks are still dominating the life of many of the poor, dependent on agricultural production, but these risks are not necessarily central to the growth and poverty tragedy in Africa: which is driven by the lack of African and foreign 
investment in Africa. In particular, the risks related to poorly functioning markets and economic and political institutions have been underresearched by microeconomists, often leaving the initiative to macroeconomic research. Six, the research on risk and its implications has to embrace more seriously the experimental and behavioural literature. The research frameworks used in most work on risk and its implications are based on shaky behavioural foundations, building on the expected utility framework but testing these foundations in the environments were risk really matters, such as the poorest settings of Africa, has largely been lacking, limiting our understanding of whether they matter.

All these points will be gradually developed in this paper. However, the next section will first revisit a simple conceptual framework structuring our economic understanding of risk and its consequences. It will also involve a discussion of the strategies used to cope with risk and shocks. Section 3 looks at the implications of shocks, in terms of its short run effects on poverty. Section 4 focuses on the long-term effects on poverty and growth. Section 5 focuses on missing links in the analysis of risk and its consequences and section 6 introduces some of the evidence from behavioural economics into the analysis. Section 7 concludes.

\section{A simple model of behaviour in the face of risk}

At the risk of stating the obvious, it is instructive to briefly revisit the standard framework for analyzing rational decision making under uncertainty. Households or firms face a multitude of risk, and given their options and characteristics, make decisions that are optimal. As seen from the point of view of households, consider the household maximising intertemporally additive utility, defined over instantaneous utility $v$. Define $\delta$ as the rate of time preference, the discount rate for future utility. Furthermore, let $v$ ' $>0$ and $v$ '" $<0$, i.e. instantaneous utility is concave, so risk aversion is assumed. Given the presence of risk, and as seen at $t$, intertemporal utility is defined as expected utility over the remainder of the household's lifetime. To focus on the fact that households may have to adjust their plans over time, we consider utility at $t$, defined as 


$$
u_{t}=E_{t}\left[\sum_{\tau=t}^{T}(1+\delta)^{t-\tau} v\left(c_{\tau}\right)\right]
$$

Let us further assume that it earns income $y_{t}$ based on deciding on some technology $x_{t}$ in each period $t$ - 1 . Even though for simplicity $x_{t}$ is a costless choice, higher $x$ represents higher returns with higher risk. The household owns assets $A_{t}$ at the beginning of period $t$, and earns an interest rate $r$ on funds held over from period $t$ into period $t+1$. There is no bequest motive. Assets evolve from one period to the next according to:

$$
A_{t+1}=(1+r)\left(A_{t}+y_{t}\left(x_{t}, A_{t}\right)-c_{t}\right)
$$

and we assume that insurance markets are missing.

This set-up helps us to focus on many issues that are relevant for the rest of our discussion. Table 1 summarizes the decisions that need to be taken. In each period, the household will have a level of assets $A_{t}$ and faces a realized income level $y_{t}$, and then it has to choose its consumption $c_{t}$, the savings of the next period $A_{t+1}$ but also the technology $x_{t+1}$ that, combined with $A_{t+1}$ will generate $y_{t+1}$ with a particular risk distribution. Decisions on $x_{t+1}$ and $A_{t+1}$ have to be taken before the risk has been resolved, i.e. ex-ante, and affect the income distribution (in terms of risk and returns) that the household will face. These decisions tend to be referred to as risk management strategies. Once an income outcome is realized - the household could be facing a negative or positive or no income shock - it may further decide to use its assets to 'smooth' its consumption, and given the assumptions underlying (1), it will do so. Selling off assets for smoothing is an example of a risk coping strategy. Especially with credit markets missing or imperfect, these decisions are not costless, and may result in seriously lower consumption or other outcomes both in the shortrun and long-run.

Table 1 Risk and outcomes

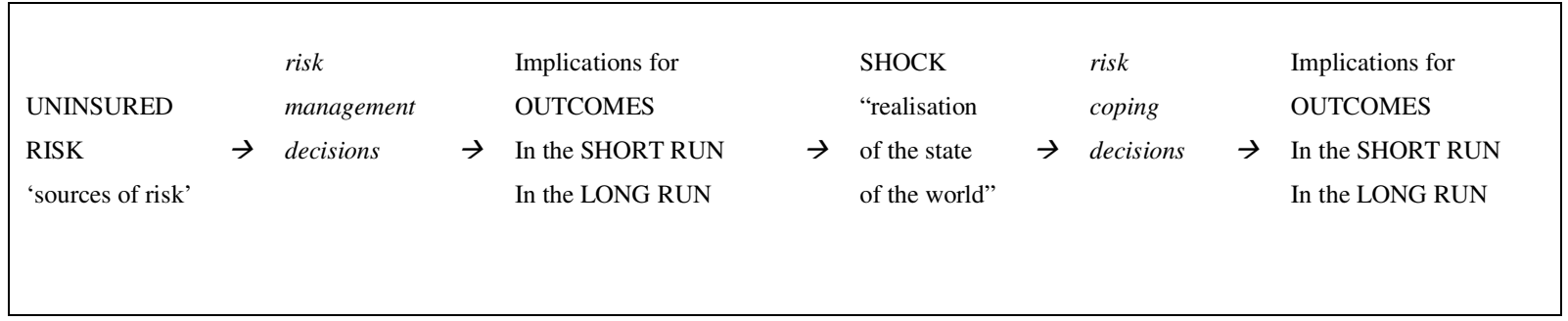


Similar models are the basis for much of the work on risk and its consequences; not all research will articulate all these dimensions. For example, adding further assumptions on the shape of preferences allows predictions related to the existence of precautionary savings behaviour. Deaton (1992) combined this with an assumption on the absence of credit markets $\left(A_{t+1} \geq 0\right)$ and exogenous risky income $y_{t}$ to derive predictions on the role of buffer stock savings in developing countries, for example analyzed in Czukas et al. (1998). Morduch (1995) focuses (inter alia) on choices of $x$ and its implications. Townsend (1994) keeps y risky but exogenous, and introduces the possibility that despite lacking insurance, efficient risk-sharing can occur within villages, via a perfectly enforceable arrangement - and tests this on data. Dercon (2002) discusses different more complex models in the literature, that share this underlying or a variation on this structure.

Indeed, a vast literature has emerged that looks these issues, including in Africa. For example, in terms of risk coping, much attention has been given to issues related to informal 'risk-sharing' arrangements: do households or individuals manage to remain unaffected by risk via such arrangements? Are they occurring within extended families, within marriage, within networks or even within the village? What sustains these arrangements? What form do they take? We have evidence on these issues on a number of African settings, for example on the way risks are shared within marriage in Ethiopia (Dercon and Krishnan, 2000), or how networks within the village matter for mutual insurance in Tanzania (De Weerdt and Dercon, 2006), or how credit contracts in rural Nigeria contain 'risk-sharing' elements (Udry, 1994). Other forms of risk-coping have also been documented, for example, how child labour increases in response to income shocks (Beegle et al. 2004). There is also evidence that asset sales are responsive to shocks, suggestive of buffer stock savings in Burkina Faso (Czukas et al., 1998). Hoddinott and Harrower (2005) suggest that in Mali coping mechanisms involve entering into new activities to earn extra income in response to shocks.

There is less evidence on risk management strategies, largely due to the higher data demands to investigate how activity and asset portfolios are affected by risk. Realized shocks are not relevant for identification of these effects, so that variation in riskexposure is needed to identify the impact of risk. The evidence on Africa is relatively 
limited, compared to evidence on Asia (Morduch, 1995). Dercon (1996) found that those with less protection against shocks specialized relatively more in drought resistant crops in Tanzania. In Ethiopia, Dercon and Christiaensen (2005) found that fertiliser use was significantly lower for those with higher consumption risk.

At this stage, it is helpful to get one crucial fallacy out of the way. It is sometimes suggested that risk is problem for some families or firms because of risk aversion. Those that take risks are less risk averse and 'entrepreneurial', it is suggested, and therefore their decisions result in lower earnings in the long run. If people were less risk averse, risk would not be a problem: risk is just a matter of choice, and preferences drive the entire outcome. The fallacy in this reasoning is that risk is only a "problem" because of the lack of insurance, and in general, missing 'risk' markets: even with risk aversion, risk does not need to have detrimental consequences, since people can enter into contracts, such as insurance. It becomes an important problem, with possibly disastrous consequences, if people do not have access to the means to protect themselves. In other words, it is a problem that should concern any policy maker when the poor lack the opportunities to choose a particular degree of protection, in line with their preferences.

There is still much to learn about the risk management and coping strategies used by households in developing countries, not least in Africa. The increased availability of panel data especially in rural settings, as well as a broader understanding of the different responses observed elsewhere provides ample opportunities for research. But there is an important weakness in much of this work: by focusing on the ingenuity of the strategies used by poor, the impression is created that they are very effective in managing and coping with risk. In the next section, this issue is explored further.

\section{The failure of coping mechanisms}

Virtually all studies looking at the sensitivity of outcomes such as nutrition or consumption to income shocks find that these shocks are partly transmitted into outcomes. In other words, consumption smoothing and risk-sharing are incomplete. It is then a useful question to ask how important is the remaining impact of shocks on 
outcomes. Using the Ethiopian Rural Household Survey, a panel data survey covering about 1450 households across the country, this was explored further in Dercon et al. (2005). The survey collected detailed data on a variety of (self-reported) shocks that affected people during the period 1999 and 2004. In the data, it was found that just under about half the households were affected by drought in this period (since 2002 was a serious drought year), but a large number of other shocks were also relevant. For example, 43 percent reported to have been affected by a death in the household, and 28 percent were affected by a serious illness in the household. Other shocks reported (by between 10 and 20 percent of households) were output price collapses, increases in input prices, crop pests and crime.

These variables were introduced as independent variables in a simple specification, linking consumption per adult in 2004 (almost 80 percent of which is basic food consumption) to initial conditions in 1999 in terms of household demographics, land, livestock, and other household characteristics, as well as community fixed effects. Different effects of shocks occurring in the early part of this period, compared to the later part were allowed for. Table 2 gives the findings. ${ }^{1}$ As can be seen, reporting a serious drought shock in the last two years is correlated with 16 percent lower consumption, while a shock in the preceding two years is still reducing consumption by 14 percent (suggesting slow recovery). A problem in local markets linked to declining crop prices or lack of demand in recent years reduced consumption by 19 percent. Note that all these shocks are typically 'covariate' - affecting many people in the same community, and by nature hard to insure. But, at the same time, many of the reported shocks, typically idiosyncratic ones, appear to have had relatively limited impact on consumption, and in any case not systematically a significant impact on those reporting the event. The only significant idiosyncratic shock relates to illness between 3 and 5 years ago, but not recent ones. One possible explanation is that some of the immediate effects of illness can be handled by mutual support and/or savings, but illness can have debilitating effects (in terms of productivity) in the medium term.

\footnotetext{
${ }^{1}$ Some caution is needed in using this information. If unobserved heterogeneity is correlated with the direct shock terms, then what we may be picking up is not the impact of the shock, but some other characteristic, correlated with observing particular shocks. Arguably, we may then be measuring that unobserved characteristic and not the impact of the shock
} 
Table 2: Impact of shocks on (log) consumption per capita, 2004

\begin{tabular}{l|l|l}
\hline & $\begin{array}{l}\text { Estimated } \\
\text { coefficient }\end{array}$ & $\begin{array}{l}\text { t statistic } \\
\text { (absolute } \\
\text { value) }\end{array}$ \\
\hline Drought, 2002-04 & -0.163 & $2.46^{* *}$ \\
Drought, 1999-2001 & -0.137 & $2.72^{* *}$ \\
Pests or diseases that affected crops, 2002-04 & -0.006 & 0.07 \\
Pests or diseases that affected crops, 1999-2001 & -0.052 & 1.05 \\
Pests or diseases that affected livestock, 2002-04 & -0.002 & 0.18 \\
Pests or diseases that affected livestock, 1999-2001 & 0.022 & 0.24 \\
Difficulty in obtaining inputs or increases in input prices, 2002-04 & 0.055 & 0.63 \\
Difficulty in obtaining inputs or increases in input prices, 1999-2001 & 0.001 & 0.02 \\
Inability to sell outputs or decreases in output prices, 2002-04 & -0.187 & $2.23 * *$ \\
Inability to sell outputs or decreases in output prices, 1999-2001 & -0.026 & 0.36 \\
Lack of demand for non-agricultural products, 2002-04 & -0.037 & 0.19 \\
Lack of demand for non-agricultural products, 1999-2001 & -0.195 & $2.28^{* *}$ \\
Crime shocks, 2002-04 & -0.018 & 0.36 \\
Crime shocks, 1999-2001 & 0.083 & 0.99 \\
Death of head, spouse or another person, 2002-04 & 0.043 & 0.69 \\
Death of head, spouse or another person, 1999-2001 & -0.001 & 0.02 \\
Illness of head, spouse or another person, 2002-04 & -0.019 & 0.32 \\
Illness of head, spouse or another person, 1999-2001 & -0.151 & $2.33^{* *}$ \\
R ${ }^{2}$ & 0.34 & 1290 \\
\hline Sample size & & \\
\hline Notes: & & \\
\hline
\end{tabular}

Notes:

1. Specification includes controls for Female headship, age head, schooling, household size, dependency ratio, land holdings (quintiles), livestock, ethnic minority, religious minority, holding official position in PA or important place in social life, all in 1999. PA dummies, month of interview dummies and perceptions of rainfall in previous harvest year are also included but not reported. 2. Standard errors are robust to locality cluster effects. * Significant at the $10 \%$ level; ** significant at the 5\% level. Source: Ethiopian Rural Household Survey 1999-2004, and Dercon, Hoddinott and Woldehanna (2005).

This inability to smooth consumption has implications for living standards. To illustrate its consequences, I focus on poverty impacts: households may drift occasionally under some socially acceptable level, possibly bounce back up and drift back in. Uninsured shocks result then in poverty fluctuations, and this is indeed what has been found in data sets. Simple simulations based on table 2 can provide an estimate of the contribution of particular shocks to poverty. In particular, consumption can be predicted for the case in which the shocks are insured, to allow some estimate of the poverty impact of shocks. It is also straightforward to calculate the contribution of each significant shock, or all shocks together to overall poverty. In line with the fact that drought is the most prevalent shock, its impact on poverty is substantial. Using a poverty line of about 62 birr, which is well below 1 US dollar in PPP, but close to the national poverty line, poverty in these data is about 47 percent. Without 
drought shocks, counterfactual poverty is 'only' about 33 percent. With all shocks insured, poverty would go down to 29 percent.

This means that poverty in 2004 is about 50 percent higher due to the occurrence of shocks. Doing the same calculations but based on a distribution-sensitive poverty measure (such as the squared poverty gap), then the impact of shocks is even larger. Even though this was arguably a difficult period in Ethiopia's recent history (including a serious drought in 2002 and the aftermath of the war with Eritrea), these impacts are substantial. It leads also to a first conclusion in this paper: even though households are using sophisticated strategies to manage and cope with risk, shocks matter. Also, at least in this context, covariate shocks appear to dominate the effects.

These figures can be viewed as a first order approximation of the poverty reduction that could be gained from improving on current policies and interventions to deal with shocks. Indeed, it is this type of concern that is behind much of the 'safety net' thinking, whereby the presence of a real risk that individuals' and families' may experience poverty episodes due to shocks justifies more intervention to avoid this. But, we have to be cautious with these results and its implications: it can be inferred from this analysis, that there is another group, arguably deserving and needing more of our attention: those that rarely if ever manage to get outcomes above the socially accepted poverty line, the destitute or 'chronic' poor. These are the two-thirds of the sample that would have been poor even without shocks, at least on the basis of their characteristics in 1999. In that view, 'safety nets' or more in general, policies that focus on managing the risks faced by people in developing countries are more of a luxury, that threaten to distract from the core activities of stimulating growth and/or reducing poverty of the 'chronically poor'. In other words, our suggestive counterfactual analysis based on table 2 may in fact undermine any claim for more attention to risk and shocks in policies to fight poverty.

But this is closely related to the way the evidence was constructed, exploring how current consumption is affected by shocks occurring in the period immediately preceding period, familiar from the literature on testing for consumption smoothing. What we are measuring in this way is the short-run impact of shocks, and none of the long-run impacts, such as the consequence of the asset losses. In the next section, the 
issue of the long-term consequences will be taken up in more detail, as it leads to a reassessment of the role of risk on poverty and growth. Its conclusions will place finding better ways to provide protection against shocks closer to the heart of growth and poverty reduction policies, as shocks will be shown to be an important cause of poverty.

\section{The long-run consequences of shocks and risk}

It is well established that poor nutrition in particular periods in a child's early life may contribute to poorer 'long-term' nutrition, in the form of stunting (height-for-age levels below some level observed in healthy populations). Short-term shocks to nutrition may then have persistent health effect. While there is evidence for this process, this is not exactly borne out by all studies: some have suggested that 'catchup' remains possible: i.e. that over time children may recover the lost nutrition and return to their personal growth curve. This is an empirical issue, and most evidence would suggest that stunting is a serious, permanent problem, not least in early years, since evidence suggests a strong correlation between child height at age three and adult height (Martorell, 1999). ${ }^{2}$

These nutritional effects may have far reaching consequences. Children with slow height growth are found to perform less well in school, score poorly on tests of cognitive functions and develop slower. Adult height is correlated with earnings and productivity, poorer cognitive outcomes and premature mortality due to increased risk of cardiovascular and obstructive lung disease. Taller women experience lower risks of child and maternal mortality. In the case of adults, an increasing body of evidence links adult weight or $\mathrm{BMI}^{3}$ (the Body Mass Index, also known as the Quetelet Index) to agricultural productivity and wages (Dasgupta, 1993; Dercon and Krishnan, 2000; Strauss and Thomas, 1998; Pitt, Rosenzweig and Hassan, 1990). Low BMI is correlated with a large number of health-related indicators, including early onset of chronic conditions and increased risk of premature mortality (Fogel, 1999).

\footnotetext{
${ }^{2}$ The discussion of the evidence is based on Dercon and Hoddinott (2004).

${ }^{3} \mathrm{BMI}$ is the Body Mass Index, defined as weight in $\mathrm{kg}$, divided by the square of height in meters.
} 
In the literature on shocks and nutrition in Africa, a close link between 'shocks' and long-term socio-economic impacts has been documented. Alderman et al. (2004) trace the impact of the 1982/83/84 droughts in Zimbabwe, as well as exposure to the civil war preceding independence, on longer-term measures of child health and education in the 1990s in a rich panel data set in particular resettlement areas. They focus on shocks if the child is in the critical 12-24 month age category - generally recognised as the most critical time for child growth. These children were interviewed again 13 to 16 years later. Using an instrumental variables-maternal fixed effects estimator, they show that lowered stature as a pre-schooler leads to lowered in late adolescence as well as delays in school enrollment and reductions in grade completion. The magnitudes of these impacts are meaningful. Using careful estimation methods, they found that the 1982/83/84 drought shock resulted in a loss of stature of 2.3 centimetres, 0.4 grades of schooling, and a delay in starting school of 3.7 months for this particular age-group. Using the values for the returns to education and age/job experience in the Zimbabwean manufacturing sector provided by Bigsten et al. (2000, Table 5), the impact of the shock translates into a 14 per cent loss in lifetime earnings.

The impact of shocks is not restricted to large 'covariate' shocks such as drought. In Tanzania, recent work has involved an attempt to trace any individual interviewed during a four round household survey conducted in 1991-1994 in Kagera Region (Beegle et al., 2006a). The survey collected detailed data on the incidence of orphanhood in this area of high HIV prevalence, and investigated the long-term implications of becoming an orphan, on a sample of children not orphaned at baseline. Table 3 reports results from the sub-sample that reached adulthood (above 19 or older) by 2004, based on a sample of non-orphans in the baseline period 1991-94, so that the effects are effectively irreversible for both height and (most likely) for education. We find that losing one's mother during childhood reduces height at adulthood by about $2 \mathrm{~cm}$, while orphans have about one less year of education than others. This translates into 8 in total... 
Table 3: Determinants of Height and Years of Schooling in 2004

\begin{tabular}{lll}
\hline & Ln height & Years of schooling \\
\hline Mother died between ages 0-15 & $-0.011^{*}$ & $-1.049^{* *}$ \\
& $(0.006)$ & $(0.452)$ \\
Father died between ages 0-15 & -0.002 & -0.360 \\
& $(0.004)$ & $(0.319)$ \\
\hline
\end{tabular}

Number of observations

681

681

Notes: OLS estimates with community fixed effects and cluster corrected standard errors.. "Reached adulthood" $(\mathrm{n}=902)$ restricts the full sample to those age 19 and older in 2004. T-statistics in brackets. * significant at 10\%, ** significant at 5\%,*** significant at $1 \%$. Includes controls for child characteristics (sex and age dummies), baseline characteristics (residing with mother and residing with father; household consumption, flooring material, age, years of education and sex of the household head). The height regressions include the height of the child at baseline and, when available, mother's height from the baseline data. The schooling regressions include the years of education of the child and whether the child was at school in the baseline. Source: Beegle et al. (2006)

Shocks may also work more subtly to generate long-term consequences. Krutikov (2006), building on Beegle et al. (2004), has evidence from the same Tanzania data set that if children end up engaging in more child labour in response to agricultural crop shocks experienced by the family, then it translates itself in permanent losses in terms of educational attainment. In other words, taking children out of school or at least burdening them with more work while at school comes at a cost in the long-run. School attainment can also be affected by shocks experienced by teachers: recent work on Zambia has shown that both child and teacher absenteeism in school, closely linked to illness shocks in the context of the HIV/AIDS epidemic, reduces cognitive achievement by children, again affecting long-term outcomes (Das et al. 2006). With education closely related to higher earning potential at adulthood, the economic consequences for those affected, and probably the rest of society, are serious.

This evidence would suggest processes in which incomes and levels of wellbeing are permanently affected by transitory shocks. It is possible to conceptualise these as poverty trap, equilibrium levels of poverty in which one may slide relatively easily, but from which there is no possible recovery without 'outside' intervention. There are many mechanisms that may result in poverty traps ${ }^{4}$; the examples suggest poverty

\footnotetext{
${ }^{4} \mathrm{~A}$ poverty trap can be defined as a $\mathrm{n}$ equilibrium outcome and a situation from which one cannot emerge without outside help, for example, via a positive windfall to a particular group, such as by redistribution or aid, or via a fundamental change in the functioning of markets. Poverty traps are often
} 
traps linked to human capital: if opportunities are missed to accumulate it (in these case, via appropriate nutrition at crucial moments during childhood, or benefiting from schooling at the right age when time should be available to do so), then a permanent state of lower human capital and earnings follows. ${ }^{5}$ Other narratives are possible. For example, Barrett and Carter (2004) use evidence from Kenya to suggest that such thresholds can be observed at least among pastoralists, given that minimum herd size are required for possible accumulation and leading to 'asset poverty traps'.

The existence of pure poverty traps is hard to prove, and mostly we have to settle for showing the existence of long-lasting effects of effects, suggesting persistent effects from one-off shocks. Contrary to standard tests for 'short-run' impacts of shocks, as used in testing for consumption smoothing, 'lagged' shocks are introduced in the analysis. Some recent studies look at the long-term 'overall' consumption outcomes from serious shocks, and find substantial effects. Dercon (2004), using a subset of the same panel data households reported in table 1, exploited detailed data on the experience during the $1984 / 85$ famine, more specifically the extent they had to resort to famine coping strategies, such as cutting meals and portions, selling valuables, relying on wild foods and moving to feeding camps. An index of these experiences in the mid-1980s was then introduced in a model of consumption growth based on data from 1989 to 1997, regressing changes in food consumption on initial levels of food consumption at the household and community level and a number of common and idiosyncratic shocks. Note that if shocks only have transitory effects, then lagged shocks should have no effect. Table 4 shows the findings. It was found that rainfall shocks several years before the period in which growth was measured, still affect growth. Most strikingly, the extent of the famine impact, as measured by the index of severity of coping strategies, strongly affected growth in the 1990s. This growth impact was substantial: depending on the estimation method, comparing the 25th and 75 percentile of households in terms of the severity of suffering, the latter had about 4 to 16 percentage points lower growth in the 1990s, a period of on average substantial recovery of food consumption and nutrition levels after crisis and war in the 1980s. Furthermore, it took on average ten years for livestock holdings, a key form of

conceptualised as caused by the presence of increasing returns, or a threshold, although other mechanisms are possible, such as credit market failures or externalities. Dercon (2004a) has a review of models relevant for poverty analysis.

${ }^{5}$ Models with increasing returns or complementarities could deliver such processes. 
savings and assets for accumulation in rural Ethiopia, to recover to the levels seen before the 1984-85 famine.

Table 4 Testing for persistent effects of shocks on food consumption growth. Dependent variable: change in ln food consumption per adult between survey waves (1989-94 and 1994-97). Hausman-Taylor and Jalan and Ravallion estimators.

\begin{tabular}{|c|c|c|c|c|}
\hline & \multicolumn{2}{|c|}{$\begin{array}{l}\Delta \ln \text { food cons } \\
\text { (1) (HT) }\end{array}$} & \multicolumn{2}{|c|}{$\begin{array}{l}\Delta \ln \text { food cons } \\
\text { (2) (JR) }\end{array}$} \\
\hline & Coeff & $\mathrm{p}$-value & Coeff & $\mathrm{p}$-value \\
\hline ln food consumption ${ }_{t-1}$ & -0.318 & 0.000 & -0.204 & 0.000 \\
\hline Village mean $\ln$ food cons $\mathrm{t}_{\mathrm{t}-1}$ & 0.211 & 0.000 & 0.135 & 0.004 \\
\hline rainfall shocks $\mathrm{t}_{\mathrm{t}}$ & 0.622 & 0.000 & 0.614 & 0.002 \\
\hline rainfall shocks $\mathrm{t}_{\mathrm{t}-1}$ & 0.069 & 0.016 & 0.195 & 0.013 \\
\hline Adult serious illness & -0.043 & 0.076 & -0.053 & 0.064 \\
\hline crop shock (-1 is worst) & -0.014 & 0.757 & -0.217 & 0.041 \\
\hline livestock shock (-1 is worst) & -0.018 & 0.704 & -0.009 & 0.910 \\
\hline severity of famine impact & -0.116 & 0.079 & -0.397 & 0.068 \\
\hline Constant & 0.519 & 0.000 & 0.920 & 0.071 \\
\hline Number of observations & \multicolumn{2}{|l|}{636} & \multicolumn{2}{|l|}{319} \\
\hline
\end{tabular}

Source: Dercon (2004), table 6. Regression (1) use the Hausman-Taylor model, and assume rainfall shocks, livestock shocks and crop shocks as time-varying, exogenous variables, and demographic changes, illness shocks and lagged consumption at household and village level as time-varying endogenous variables. The index of the severity of the crisis experienced (coping index) was treated as time-invariant exogenous, as was (if applicable) whether there was a road available. As time-invariant exogenous variables and instruments, the presence of harvest failure during the famine period, the estimated percentage of households suffering in each village and the ln of livestock before the famine were used. Regression (2) uses the Jalan-Ravallion estimator (Jalan and Ravallion (2002)).

In Beegle et al (2006b), using the same data set on Tanzania as reported on in table 3, the issue of the impact of a prime-age adult mortality shock up to 13 years later on consumption outcomes, as well the impact of serious agricultural crop shocks, were investigated. Recall that the high frequency of these adult shocks is closely linked to HIV-AIDS. More than a quarter of the households reported an prime-age adult death in this period. An area with generally relatively good agro-climatic conditions, about 16 percent reported crop shocks mainly related to pests and drought. Using data which tracks individuals from 1991-2004, we examine consumption growth, controlling for a set of initial community, household and individual characteristics; the effect is identified using split-offs in 2004 of baseline households. Table 5 shows the basic results, in which shocks are introduced, allowing for the timing during which they occurred. The paper finds robust evidence that an affected household will see consumption drop with $7 \%$ within the first five years after the prime-age adult death. 
With high consumption growth in the sample in this period, this creates a 19 percentage point growth gap with the average household. There is some evidence of persistent effects of these shocks for up to 13 years, but these effects are imprecisely estimated and not significantly different from zero. The impact of female adult death is found to be particularly severe. Crop shocks have significant persistent effects, with consumption outcomes in 2004 affected by shocks occurring up to 13 years ago. ${ }^{6}$

Table 5: Consumption growth 1991-2004 in KHDS Tanzania: effect of a prime-aged death (20-55 yrs.) of a baseline respondent on survivors (Initial Household Fixed Effects)

\begin{tabular}{lc}
\hline & Consumption growth 1991-2004 \\
\hline Death 1991-1995 & -0.111 \\
& {$[0.171]$} \\
Death 1996-1999 & -0.149 \\
& {$[0.157]$} \\
Death 2000-2004 & -0.298 \\
& {$[0.130]^{* *}$} \\
Crop Shock 1991-1995 & -0.398 \\
& {$[0.223]^{*}$} \\
Crop Shock 1996-1999 & -0.191 \\
& {$[0.114]^{*}$} \\
Crop Shock 2000-2004 & -0.168 \\
& {$[0.088]^{*}$} \\
\hline Observations & 2,281 \\
\hline Notes: Initial household fixed effects regressions. Unit of observation are households in 2004. \\
Regressions control for average baseline characteristics of the panel individuals in these households \\
(mean years of education, share of males, share of chronically ill and mean number of biological children \\
living outside). * significant at 10\%; ** significant at 5\%; *** significant at 1\%. \\
\hline
\end{tabular}

All this evidence is related to a persistent or permanent effect from a serious shock, so that uninsured risk is a cause of poverty. Much of this evidence is based on a handful of data sets and settings; we need more evidence to be able to generalize the importance of these effects. Another conclusion follows: these long-run implications of shocks are far more striking and suggest a much more important policy-relevance of this work. If shocks have long-run implications that are as large in terms of incomes and growth as these findings are suggesting, then finding ways of avoiding

\footnotetext{
${ }^{6}$ It should be noted that the presence of persistent effects for up to five years was also found in table 1 in Ethiopia, since the regression investigated the impact of shocks of up to five years ago on consumption outcomes in 2004. In other words, we find that for example a drought shock in 1999-2001 still affects consumption outcomes up to five years later, a clear sign of persistence.
} 
these impacts are crucial for policy fighting poverty. Given that the foundations for growth are affected as well, via losses in human and physical capital, it may well be crucial for growth in these countries as well. In other words, providing social protection has high economic and social benefits in terms growth and poverty, well beyond the peripheral benefits that reduce the implications of shocks to mere "welfare fluctuations' deserving some basic safety net.

However, this literature has an important weakness as well. It appears to convolute 'risk' with 'shocks': the analysis tends to focus on disasters for families and communities ('fate') rather than the fear and threat of disaster and the risk avoidance behaviour that may follow in terms of activities and assets. The approach taken above is to link observed shocks to outcomes, which is effectively focusing on the imperfections in coping mechanisms, or the second part of table 1. In the face of risk, and given failing insurance and credit markets, households will engage in risk management strategies, changing their investment and activities to limit their exposure to risk. In the previous section, examples were given, such as diversifying activities, not engaging in more risky activities and changing asset portfolios to keep limit holdings of risky assets. It is important to try to quantify the implications of these risk management strategies, since none of the analyses reported above would be able to pick up these effects. In fact, if households responded to high risk by moving away from activities that involve exposure to weather risk or market risk (for example by growing a very low return but highly drought resistant crop that no-one really wants to buy), then in the regressions in table 2, 4 or 5 for Ethiopia and Tanzania, agricultural or market risk variables would be unrelated to outcomes. But to state that risk has no impact would then be a fallacy. Only relatively few papers exist on African data that try to quantify this 'ex-ante' or 'risk-management' effect on incomes or assets.

One paper, by Dercon (1996), finds suggestive evidence for this effect in Shinyanga region in Tanzania, even if the evidence is not conclusively showing that it is all about risk. The paper shows Tanzanian households with limited liquid assets (livestock) grow proportionately more sweet potatoes, a low-return, low-risk crop. A household with an average livestock holding allocates 20 percent less of its land to sweet potatoes than a household with no liquid assets. The crop portfolio of the wealthiest 
quintile yields 25 percent more per adult than that of the poorest quintile. Choosing a less risky crop portfolio thus has substantial negative consequences for incomes.

In a careful study, Elbers and Gunning (2003), use simulation based econometric methods to calibrate a growth model that explicitly accounts for risk and risk management responses, applied to panel data from rural Zimbabwe. They found that risk substantially reduces growth, reducing the capital stock (in the steady state) by more than 40 percent. Two-thirds of this loss is due to ex-ante strategies by which households try to minimize the impact of risk, i.e. the build-up of livestock holdings to cope with consumption risk. Dercon and Christiaensen (2005), using the same data set on Ethiopia discussed above, find a significant increase in fertiliser use if some insurance were to be offered against downside consumption risk, since when rains fail, financial returns to fertiliser use are typically very low. They reach this conclusion of finding significant sensitivity of fertiliser use to the predicted levels of consumption when rains were to fail, despite controlling for actual current levels of assets, so that the problem is not just a problem of seasonal credit or working capital. They find that fertiliser application rates would increase by about 8 percent if downside risk could be insured.

This is definitely an area that requires more attention in research. The challenge is to identify risk, rather than shocks, and then trace the implications of uninsured risk via behavioural responses, in the form of its impact on activities, assets and technology choices. Such behavioural responses would provide mechanisms by which poverty persists, since the best that poor people can do is to make choices that perpetuate poverty via choosing low return, low risk portfolios of activities and assets. As the evidence points towards such effects, this clearly has important implications for the design of policies, putting policies to reduce risk and its consequences at the core of growth and poverty reduction efforts.

However, despite the growing evidence base, it is striking that these concerns and this evidence does not appear to have as much impact on, say, many policy economists closely concerned with growth or pro-poor growth issues. This is discussed in the next section. 


\section{Missing links in the analysis of risks and its consequences}

There are a number of problems with the available evidence on risk and its consequences. A first problem is that we have to rely on risks that relatively easily measured. The long-term shocks identified in all the studies quoted before are based on shocks recorded in survey data (such as drought shocks, adult mortality, crop shocks) or shocks easily measured because of the availability of secondary data (such as on rainfall). The impact of risk on activities and assets is based on inference or calibration from within surveys, or in Dercon and Christiaensen (2005), rainfall distributions from secondary sources.

A second problem is related to the history of much of this literature on risk and its consequences in developing countries. The analysis of risk has long been a particular area of attention for agricultural economists. Furthermore, panel data are typically needed for exploring these issues related to risk and the collection of panel data in developing countries has been found more easily and has definitely been more successful in rural settings. For example, the first widely used panel data sets in developing countries in India and Burkina Faso were collected by a crop research institute, ICRISAT, by a team of economists with a particular interest in rural agricultural issues, as well as risk.

The result is that most of the data with specific risk focus were collected in rural settings, on households engaged in agriculture. Firms have rarely been surveyed with a clear risk perspective or the data from these surveys have rarely been analyzed using risk and its consequences as the focal point ${ }^{7}$. Few urban surveys and analyzes have been able to successfully ask and address risk issues.

This has clearly limited the type of work and questions that have been explored. In fact, a clear gap emerges with some of the main concerns preoccupying macroeconomists concerned with growth. For example, there is little micro-evidence on the impact of conflict risk on growth and activity portfolios using micro-level data, even though conflict is shown to affect growth considerably using macro-data (Collier

\footnotetext{
${ }^{7}$ An interesting exception is Fafchamps et al. (2000), which looks at how inventories are affected by risk in Zimbabwe.
} 
and Hoeffler, 2006). In principle, very similar processes are likely to take place as described in table 1: conflict may result in the need to use risk coping strategies, or assets may be directly lost due to violence and war, while the risk of conflict is also bound to result in asset and activity portfolios. For example, it can be expected that few activities with sunk costs will be tried, even at the cost of lower returns, or that asset portfolios will be skewed towards assets that can be easily hidden, transported and liquidated (such as jewelry or cash). The lower returns to gain more security would provide a direct and relevant cost to conflict risk. In the context of Africa, Deininger (2003) provides some attempt at analyzing the impact of civil war related conflict on activities using a household panel data linking 1992 to 2000 . He finds, within the confines of his data, that households in communities with a higher 'risk' of civil strife engage less in new off-farm activities while more of their business are stopped.

Governance problems are similarly increasingly at the centre of attention of those concerned with failing growth and persistent poverty in Africa. Poor institutions and corruption may result in some people to be specifically affected by having to pay a bribe - and we could in principle quantify the asset and income losses involved and their long-term consequences. But a more crucial consequence of such an environment of poor rule of law and corruption would be that asset and activity portfolios are changed: extra investment, such as in lawyers, corrupt officials or the mob will have to take place, making some activities simply too costly to get involved in. The result would be that rather than running the risk of having to pay high bribes to build up an activity, the nature of investment is changed. Some evidence on Africa suggests such phenomena. Svensson (2003), using data from firms in Uganda, finds that there is a negative correlation between the amount of bribes a firm has to pay and the reversibility of the capital stock. One way of reading this evidence is that firms that cannot easily bear the consequences of bribe attempts move towards technologies and asset portfolios that reduce their risk of exposure to bribes - not dissimilar to the model and table 1 developed earlier.

There is one strand of the literature that addresses some of these institutional risks more directly, but that strikingly it does not tend to be linked directly to the literature on risk and its consequences: the work on land tenure rights and security, including in 
Africa. This research tends to be done in the context of debates on property rights and their incentive effects; however, once property rights are not totally secure, similar decision making and consequences as described in table 1 can be found. In practice, despite some insecurity of land rights in many African countries, there is little evidence on the consequences of loss of land due to expropriation, even though in some context the prevalence of such shocks is remarkably high. For example, in Ethiopia, in the sample used for tables 2 and 4, the second most common 'shock' causing hardship (after drought) during the period 1975-94 had been reported to be related to loss of land via land redistribution and villagisation. By 1999, it was found that almost 40 percent of the sample had lost land at one time or another. The context is of course exceptional, with land state-owned since 1976, and with repeated land reforms and reallocations occurring until fairly recently, as a means of offering land to new households, returning soldiers and other 'deserving' groups.

The impact of tenure insecurity on investment (in other words, the way risk is managed in terms of asset portfolios given land risk) has been relatively widely studied, highlighting the efficiency losses due to insecurity, for example see Besley (1995) as well as Goldstein and Udry (2006) on Ghana. In Ethiopia, Deininger and Jin (2005) document the impact of tenure insecurity on land related investment. Dercon et al. (2006) identify the impact of tenure insecurity via changes in perceived security on changes in land areas allocated to coffee and other perennials, and find that coffee plantings may well be about a fifth higher is farmers were to have secure rights.

In short, there appears to be an artificial distinction between the literature on risk and its consequences, and the specific literature focusing on more 'institutional' issues such on conflict, the rule of law, property rights and corruption. However, the underlying analytical and empirical framework for much of the relevant questions is not very different: land expropriation, crime or conflict may be important causes for 'shocks' requiring particular coping mechanisms, while the risks 'ex-ante' may induce costly behaviour in terms of avoiding profitable activities, investments or asset portfolios. $^{8}$

\footnotetext{
${ }^{8}$ One crucial difference between these 'institutional' risks and those commonly researched, such as related to mortality or drought is that the public response is very different. Policy makers The latter tends to attract discussion on 'safety nets', via transfer in cash or in kind, or employment generation.
} 
More work is needed to find ways of identifying risk in urban and firm settings. It is not altogether clear how self-reported 'events' can inform this analysis, while there is unlikely going to be an equivalent large covariate risk factor with good quality data and geographical variation (such as 'rainfall' in rural settings) that could serve as the relevant source of exogenous variation. The strategy may have to be to use surveybased techniques combined with imaginative methodological innovations, such as identifying natural experiments on some of these other sources of risk. ${ }^{9}$

The data one would like to have access to for a more complete analysis of risk and its consequences on growth and poverty are similar to the risk dimension of what tends to be referred to as the 'investment climate'. In fact, interesting work has been taking place by the World Bank in collecting this type of data at the level of firms in a large number of countries on a comparable basis. ${ }^{10}$ It provides an assessment of the extent of a variety of problems, as well as details on the costs involved of trying to deal with problems (such as spending on security) besides some more general firm characteristics. Unfortunately, the nature of the data collected seriously limits any possibility of assessing impact of the investment climate. In fact, I cannot help sensing that the main interest was to collect data to lead to aggregate characteristics that could be compared across countries (and so could be fed into cross-country regressions for analysis) rather than actually fostering a deeper understanding of how investment climate matter for actual investments in each context. The data are only a cross-section, with very limited scope for analysis on dynamic investment consequences, seriously affecting the possibility for assessing any causality as well as the scope for quantification of the impact of different factors (Söderbom, 2005). ${ }^{11}$

More broadly speaking, the responses are in sphere of (social) insurance. No-one would argue that institutional risks are best handled by insurance; prevention of these risks occurring is the much more obvious response - from peace-building to developing legal institutions or secure rights. The point made in the paper is however that analytically, once risk is there, the analysis of its consequences is remarkably similar.

${ }^{9}$ Of course, there is a more general problem facing the empirical researcher: if the investment climate, for example related to the risks related to investment are very substantial, whether in a rural, urban or firm setting, so that a set of technologies, assets and activities are simply not entered into, then assessing the growth and poverty consequences of these risks in not possible since there is no variation to identify its impact.

${ }^{10}$ See http://iresearch.worldbank.org/ics/jsp/index.jsp

11 Another issue is that most of the questions appear to try to capture the 'costs' of the investment climate in terms of higher marginal costs due to problems. Such a cost approach ignores the other part of the investment climate of interest in this paper, the risk related to investment. 
In conclusion, work on risk and its consequences in Africa needs to go beyond the rural settings and the typical rural and life-cycle risks it has focused on. While evidence from these settings suggests important permanent effects relevant for poverty and growth, the standard work ignores other risks such as 'institutional' risks. There appears to be much scope to use some of the frameworks for analyzing risk and its consequences on these other types of risk, including focusing on activity and investment portfolios. A key issue is measuring and identifying these risks convincingly.

\section{Behavioural Challenges}

In this final section, a few issues are raised related to the identification of risk and its implication for activity and asset portfolios. There typically are two sources of data on risk used in analysis. First, there is 'objective' data, such as rainfall distributions based on recorded data. Secondly, there is self-reported data, based on recording shocks or based on hypothetical data to elicit perceived distributions. These different sources are all potentially problematic, but not least in developing country context, we do not know of their relevance, providing many fruitful issues for further research.

First, self-reported data on health are well-known to be suffering from reporting bias (Strauss and Thomas, 1996). Whether this matters for all self-reported data is not easily assessed, but given their widespread use, it would be worthwhile to investigate this. Secondly, for investment behaviour it is not actual risk but perceived risk what matters. This would provide an argument for using self-reported data, but given the potential problems with these data, it may be preferable to at least instrument any selfreported data with measured data if available.

There is nevertheless a related issue, on which more evidence could be very interesting. Prospect theory as promoted by Kahnemann and Tversky (1979), building on numerous empirical experiments argues that people overestimate the probability of low probability events and underestimate the probability of higher probability events. Bernstein (1996) quotes one of Tversky's experiments based on 120 Stanford graduates, asking to them to estimate the probability of dying from various causes 
(table 7). The most notable aspect of the estimates is that the subjects significantly underestimated the probabilities for more common natural causes and vastly overestimated the probabilities for far less common unnatural causes.

Table 7 Estimates of Probabilities of Death from Various Causes (based on Tversky as reported by Bernstein (1996)).

\begin{tabular}{l|c|c}
\hline Cause & Subject Estimates & True Probabilities \\
\hline Heart Disease & 0.22 & 0.34 \\
Cancer & 0.18 & 0.23 \\
Other Natural Causes & 0.33 & 0.35 \\
$\quad$ All Natural Causes & 0.73 & 0.92 \\
& & \\
Accident & 0.32 & 0.05 \\
Murder & 0.10 & 0.01 \\
Other Unnatural Causes & 0.11 & 0.02 \\
$\quad$ All Unnatural Causes & 0.53 & 0.08 \\
\hline
\end{tabular}

Note: based on a sample of 120 Stanford graduate students

Kahnemann and Tversky (1979) and other evidence goes a step further, and suggest that especially low probability events with disastrous effects tend to get an overestimated weight. If confirmed in settings in Africa, then even though particular risks, such as expropriation may feature relatively lower in terms of realisations in some countries, responses in terms of assets and activity portfolios may be more substantial than may seem objectively warranted. The overestimation of these risks may come at substantial costs in terms of foregoing investment opportunities.

The evidence in table 7 draws on behavioural economics, a branch of economics that, with inspiration from psychology, is trying to investigate and take into account behaviour as it appears to take place, even if not quite consistent with the rational choice framework more usually applied in economics. Most researchers working on risk and its implications for poverty and growth have generally ignored this work. Behavioural economics is on the ascent and further work on risk cannot just ignore this. Formal modelling tends to be based on expected utility, explicitly identifying risk aversion in outcomes and/or wealth. The challenges posed by the behavioural evidence are not taken into account. Some complicated discounting, discontinuous functions, fanning out of low probabilities and other 'tricks' can be applied to rescue expected utility, but this may not be a satisfactory route to go. 
Some caution is nevertheless warranted in terms of embracing all findings from behavioural economics. There are in fact excellent reasons why one should not necessarily go in that direction: it redirects the focus of many observed outcomes back into the sphere of preferences, drawing attention away from the bread and butter of the economist, focusing on how constraints shape behaviour and outcome. Arguably, when dealing with risk and poverty, preferences are not the sphere we should start work: as argued earlier, risk fundamentally only matters for behaviour because insurance markets fail, and it matters only a great deal for poverty because the lack of insurance and other mechanisms to deal with it imply ex-ante ex-post strategies and particular poverty and growth outcomes. It took a lot of work and effort of researchers to elucidate how the role of different market failures means that simply reducing observed behaviour to 'risk aversion' on the part of the poor is misleading. As Kochar (1995) notes, "the set of options faced by farmers offers little role for preferences" (p. 159). The behaviour of the poor with few insurance possibilities may look as if they have more (innate) risk-averse preferences, but it is the lack of insurance and credit, and the set of options available to them that forces them to take less risk and therefore forego income (see Eswaran and Kotwal, 1989, for a careful theoretical discussion). ${ }^{12}$

Even if some of the emerging behavioural literature may seem opportunistic, one cannot just ignore it, in order to focus rightful attention on the policy implications of failing markets for the poor, not least since the work on risk is probably the best established of all work on behavioural economics. Three strands can be mentioned, which despite apparent suggestions to the contrary, are not easily squared in a general theory of behaviour towards risk, let alone a clear representation of preferences. First, loss aversion: people may well have a calculus focusing on losses, so that at any point of wealth, a loss is much more heavily valued than a gain. Secondly, as mentioned before, a relatively higher weight is attached to low probability events. Thirdly, when comparing two losses, risk loving behaviour may apply to the larger losses. More specifically, if there is a choice between a moderate loss with certainty, and a far greater loss with some large non-zero probability and a small probability to make only

\footnotetext{
${ }^{12}$ A possible source of confusion in the literature is the concept of 'asset integration' (see for example, Newbery and Stiglitz, 1981), arguing that risk preferences should be measured relative to final wealth levels. With imperfect credit and insurance markets, wealth is a constraint in the choice set and other constraints could be entered in assessing the behaviour towards risk, but this is arguably different from assessing preferences, before constraints on choices are considered.
} 
a small loss, in experiments, people mostly choose the latter option: they hold on to the hope that they may not lose very much, even if with small probability, even though the expected outcome could be a very serious loss.

Loss aversion is probably best established and most widely accepted. Its dependence on a reference point is difficult to translate in normative analysis (i.e. what to do about it?). But it does not have to undermine most of the existing evidence on the importance of downside risk for people, not least for those who find it hard to protect themselves. The third issue, on risk seeking behaviour when faced with losses may well be relevant especially during crisis periods: for example, it is well recorded that during crises, such as the 1984-85 famine in Ethiopia, farmers desperately held on to their livestock, rather than selling in time, even at the expense of many of their household members' and their own life. The possibility of losing only little, however remote, may induce this risk-seeking behaviour.

This discussion on the implications of behavioural economics can at best be considered tentative. Given the central importance of risk in Africa, it would be a crucial and relevant direction of research to replicate and develop some of the experiments related to loss aversion and on risk perceptions, to establish their relevance. Furthermore, the implications for policy deserve more attention as well.

One paper, Humphrey and Verschoor (2004), starts offering some evidence from Africa, finding the reverse to the more standard results related to the weights attached to low probability events. In Uganda, they find in some specific experiments that farmers attach lower weights to low probability events. More of this and similar experimental evidence would be needed to explore the implications for both our conceptualisation of risk in Africa and its policy implications.

\section{Conclusions}

This paper revisited some of the evidence on risk and its consequences in Africa. Rather than offering a complete review, it mainly focused on some outstanding issues 
and concerns in this literature. The paper made six points. First, it argued that much of the literature on risk has not focused enough on its implications in terms of poverty and growth. Second, much of the empirical work on risk in developing countries has focused largely on short-run implications, and has ignored the long-run. In recent years, more evidence has emerged on the long-term implications of serious shocks on human capital formation and overall growth. Third, the policy implications of reducing the impact of shocks are well beyond an impact in terms of welfare fluctuations; reducing the impact of shocks is likely to have an important impact on poverty and possibly growth. Fourth, research has often conflated the consequences of serious negative events ('shocks') from the implications for economic behaviour related to living in a highly insecure environment ('risk'), specifically in terms activity, asset and investment portfolios. Fifth, much of the microeconomic research on risk has limited itself to work on risks that are 'easy' to analyze, such as rural and weather shocks. Risk faced by firms and in urban settings have not received sufficient attention. In particular, the risks related to poorly functioning markets and economic and political institutions have been underresearched. Finally, there is much scope for more work in an African context on testing insights from behavioural economics related to risk.

\section{Bibliography}

Alderman, H., J. Hoddinott and B. Kinsey (2004). 'Long term consequences of early childhood malnutrition'. Mimeo, Department of Economics, Dalhousie University, Halifax, Canada.

Barrett, C.B. and M. Carter (2004), "The Economics of Poverty Traps and Persistent Poverty: An Asset-based Approach”, Cornell University, mimeo.

Beegle, K., R. Dehejia and R. Gatti (2006) "Child labor and agricultural shocks" Journal of Development Economics, 81, (1), 80-96 2004

Beegle, K., J. De Weerdt and S.Dercon (2006a), "Orphanhood and the long-run impact on children", mimeo.

Beegle, K., J. De Weerdt and S.Dercon (2006b), “Adult Mortality and Consumption Growth in the Age of HIV/AIDS", mimeo.

Bernstein, P. (1996), Against the Gods: The Remarkable Story of Risk, John Wiley \& Sons, New York. 
Besley, T., (1995). "Property Rights and Investment Incentives: Theory and Evidence from Ghana", Journal of Political Economy, 103(5), 903-937.

Bigsten, Arne et al., (2000). 'Rates of return on physical and human capital in Africa's manufacturing sector', Economic Development and Cultural Change, Vol.48, 801-828.

Czukas, K., Fafchamps, M. and C. Udry (1998), 'Drought and Saving in West-Africa: Are Livestock a Buffer Stock', Journal of Development Economics, Vol.55, No.2, 273-305.

Das, J., S. Dercon, J.Habyarimana and P. Krishnan (2006), "Teacher Shocks and Student Learning: Evidence from Zambia”, forthcoming, Journal of Human Resources.

Dasgupta, P., (1993). An inquiry into well-being and destitution, Oxford: Oxford University Press.

De Weerdt, J. and S. Dercon (2006), "Risk-sharing networks and insurance against illness," Journal of Development Economics, Elsevier, vol. 81(2), pages 337-356, December.

Deaton, A. (1992), Understanding Consumption, Oxford: Clarendon Press.

Deininger, K. and S. Jin, 2005. "Tenure security and land-related investment: Evidence from Ethiopia”, European Economic Review, Volume 50 (5): 1245-1277

Deininger, K, (2003), "Causes and Consequences of Civil Strife: micro-level evidence from Uganda" Oxford Economic Papers, 55 (4):579-606

Dercon, S. (2004), Insurance against Poverty, Oxford: Oxford University Press.

Dercon, S. (1996), 'Risk, Crop Choice and Savings: Evidence from Tanzania', Economic Development and Cultural Change, Vol.44, No.3, 385-514.

Dercon, S. (2002), 'Income Risk, Coping Strategies and Safety Nets', World Bank Research Observer, Vol.17, 141-166.

Dercon, S. (2004), "Growth and Shocks: Evidence from Rural Ethiopia", Journal of Development Economics, August.

Dercon, S. (2004a), "Poverty traps and Development: the efficiency-equity trade-off revisited", in AFD, Poverty, Inequality and Growth, Proceedings of the AFDEUDN Conference 2003.

Dercon, S., J. Hoddinott and T. Woldehanna, (2005), "Vulnerability and shocks in 15 Ethiopian Villages, 1999-2004“, Journal of African Economies, 14(4):559-585. 
Dercon, S. and P. Krishnan (2000), 'In Sickness and in Health: Risk-Sharing within Households in Ethiopia', Journal of Political Economy, Vol.108, No.4 (August), 688-727

Dercon, S. and J. Hoddinott (2004), chapter 6 in S. Dercon, Insurance against Poverty.

Dercon, S. and L. Christiaensen, 2005, “Consumption Risk and Technology Adoption in rural Ethiopia", mimeo.

Dercon, S., D. Ayalew and M.Gautam (2006), "Land Rights and Investment in Ethiopia", mimeo.

Eifert, B., A.Gelb and V.Ramachandran (2005), "Business Environment and Comparative Advantage in Africa: Evidence from the Investment Climate Data", Center for Global Development, Working Paper 56.

Elbers, C., and J. Gunning (2003), "Growth and Risk: Methodology and Microevidence", Tinbergen Institute Discussion Papers, 03-068/2..

Eswaran, M. and A. Kotwal (1989), 'Credit as Insurance in Agrarian Economies', Journal of Development Economics, Vol.31, No.1, 37-53.

Fafchamps, M. (2003), 'Rural Poverty, Risk and Development', Elgar Publishing.

Fafchamps, M., J.W.Gunning and R.Oostendorp (2000), "Inventories and Risk in African Manufacturing”, Economic Journal, 110(466): 861-893.

Fogel, R.W. (1999). 'Catching up with the economy'. American Economic Review, Vol. 89, 1-21.

Harrower, S and J. Hoddinott, (2005), "Consumption Smoothing in Zone Lacustre, Mali”, Journal of African Economies 14(4):489-519

Humphreys, S. and A. Verschoor (2004), "Decision-making under Risk among Small Farmers in East Uganda”, Journal of African Economies, 13(1), 44-101.

Kahnemann, D. and A. Tversky (1979), "Prospect Theory: An Analysis of Decision under Risk." Econometrica, 47:263-91.

Kochar, A. (1995), 'Explaining Household Vulnerability to Idiosyncratic Income Shocks', AEA Papers and Proceedings, American Economic Review, Vol.85, No.2, 159-64.

Krutikov, S. (2006), "The Long Term Consequences of Child Labour", Centre for the Study of African Economies, mimeo.

Morduch, J. (1995), 'Income Smoothing and Consumption Smoothing', Journal of Economic Perspectives, Vol.9 (Summer), 103-14. 
Martorell, R. (1999). 'The nature of child malnutrition and its long-term implications'. Food and Nutrition Bulletin, Vol. 20, 288-292.

Newbery, David M. and Joseph E. Stiglitz, (1981) The Theory of Commodity Price Stabilization: A Study in the Economics of Risk, Oxford: Clarendon Press.

Pitt, M., M. Rosenzweig and MD Hassan (1990). 'Productivity, health and inequality in the intrahousehold distribution of food in low income countries'. American Economic Review, Vol. 80, 1139-1156.

Soderbom, M. (2005), "The Investment Climate, Private Sector Performance and Poverty Reduction in Africa”, Global Poverty Research Programme, comment, April.

Strauss, J. and Thomas, D. (1998). 'Health, Nutrition, and Economic Development", Journal of Economic Literature, Vol.36, No.2, 766-817.

Svensson, J. (2003), "Who Must Pay Bribes and How Much?" Quarterly Journal of Economics, 118:1, pp.207-30.

Townsend, R.M. (1995), 'Consumption Insurance: An Evaluation of Risk-Bearing Systems in Low-Income Economies', Journal of Economic Perspectives, Vol.9 (Summer), 83-102.

Townsend, R.M. (1994), 'Risk and Insurance in Village India', Econometrica, Vol.62, No.3, 539-91.

Udry, C. (1994), 'Risk and Insurance in a Rural Credit Market: An empirical Investigation of Northern Nigeria' Review of Economic Studies, Vol.61, No.3, 495-526.

Udry, C. and M.Goldstein, (2005), "The Profits of Power: Land Rights and Agricultural Investment in Ghana" mimeo. 